DOI 10.1515/linpo-2017-0014

\title{
On the C/edge linking mechanism. Evidence from Polish ${ }^{1}$
}

\author{
Aldona Sopata \\ Institute of Applied Linguistics, Adam Mickiewicz University in Poznań \\ sopata@amu.edu.pl
}

\begin{abstract}
Aldona Sopata. On the Cledge linking mechanism. Evidence from Polish. The Poznań Society for the Advancement of the Arts and Sciences, PL ISSN 0079-4740, pp. 87-100

The main aim of the paper is to examine Polish data from the perspective of Sigurðsson's $(2011,2014)$ theory of C/edge linking. The crucial point of the theory lies in the hypothesis that phases are equipped with silent edge features which enable narrow syntax to link to context. All definite arguments, overt as well as null arguments, must be successfully C/edge linked, e.g. they have to match at least one feature in the broad C-domain.

The present study focuses on utterances in Polish with direct object expressed as pronoun or null.The account proves successful in explaining some distributional patterns of null vs. pronoun objects in Polish. The Polish data investigated in this study indicates that the theory of silent edge linkers providing a communication channel for syntax and context is a step towards understanding the relation between syntax and pragmatics better.
\end{abstract}

Keywords: C/edge linking, context linking, null arguments, argument drop, discourse drop

\section{Introduction}

The question of the interface between pragmatics and syntax has been a matter of a debate of late. Pragmatic features have syntactic reflexes and are claimed therefore by some scholars to be encoded in the syntax (Sigurðsson 2004, 2010, 2011, 2014; Speas 2004; Haegeman \& Hill 2013 inter alia). On the one hand, language is context free because it is possible to build well-formed structures without regard to the meaning of their elements (Chomsky 1957). On the other hand, utterances are embedded in context, which can be clearly seen in the use of referential expressions that cannot be interpreted without a some specific context. Choosing referential expressions requires speakers to integrate phonological, morphological, syntactic, discourse and pragmatic information alongside visual information. The distribution patterns of overt and null referential arguments provide, therefore, insight into the nature of the mechanisms that constrain the syntax, discourse and pragmatic interface.

${ }^{1}$ The research for this paper was supported by a grant from National Science Centre, Poland, 2014/15/G/ HS6/04521. 
The present study seeks to explain the Polish data on the basis of Sigurðsson's (2011, 2014) theory, following on the idea that phases are equipped with silent edge features which enable narrow syntax to link to context. The study focuses on utterances with pronoun or null in direct object position in Polish. Scrutiny of these phenomena suggests that their distributional patterns can be interpreted as an indicator for the existence of silent edge linkers providing a communication channel for syntax and context.

The paper is organized as follows. In section 2 I present pragmatic and syntactic perspectives on referential expressions. This is followed in section 3 by a discussion of the theory of C/edge linking of referential arguments (Sigurðsson 2011, 2014). Section 4 presents the C/edge linking mechanism in the case of different types of null arguments in various languages. In section $5 \mathrm{I}$ discuss the evidence for the C/edge linking mechanism from Polish and propose an explanation of the data based on this theory. Section 6 includes the summary and conclusions.

\section{Referential expressions from the pragmatic and syntactic perspective}

Referential expressions in natural languages vary from indefinite descriptions and definite nominal phrases (NPs) through pronouns to null arguments. Gundel et al. (1993) have proposed a Givenness Hierarchy, with the cognitive statuses of referents determining the form of referential expression which speakers may choose: in focus, activated, familiar, uniquely identifiable, referential and type identifiable. Each cognitive status is, according to Gundel et al. (1993), a sufficient and necessary condition for the use of different forms. The accessibility status of a referent is determined by many factors, such as the referent's information status (givenness, salience), frequency and recency of mention in prior discourse, the referent's structural position in the preceding utterance, animacy, uniqueness and a number of possible referents mentioned in prior discourse or visible in the scene of a conversation, among others. From a pragmatic perspective, the possible referents are present in the speaker's mind, with the aforementioned factors creating a different activation value (see Arnold \& Griffin 2007; Fukumura et al. 2010; Serratrice 2013). Additional variables, such as mention of other possible referents can influence the speaker-internal level of attention resulting in the use of more or less informative forms. The choice of referential expressions is pragmatically determined by the complex mental representation of the discourse and by the amount of information needed for the conceptualisation of referents. The use of pronouns or null arguments requires a high degree of activation of the referent in the speaker's and hearer's cognitive state, i.e. it has to be highly accessible, salient or in focus (e.g. Ariel 1990; Grosz et al. 1995).

The usage of referential expressions is syntactically constrained as well. The syntactic constraints are best visible in the case of referential null arguments. According to their syntactic properties, three types of referential null arguments have been distinguished (e.g. Huang 1984, 1991; Holmberg 2005):

- pro drop, exemplified by null subjects in Romance languages and null objects in Pashto, conditioned by subject-verb or object-verb agreement, 
- topic drop, exemplified by null subjects and objects in Topic position in Germanic languages, conditioned by an empty Spec,C,

- discourse drop, exemplified by null subjects and objects in Chinese, conditioned by discourse and not clause-internally constrained.

\section{Theory of C/edge linking}

All clause elements are part of the clausal computation, which values them in relation to features of the elements in the discourse and pragmatic context. The computation mechanism can be split, however, into the process of reference connected with context scanning, and the process of $\mathrm{C} /$ edge features matching, which takes place within narrow syntax. The notion of C/edge linking was introduced by Sigurðsson $(2011,2014)$. In accordance with Frascarelli (2007), Sigurðsson assumes that several features, such as aboutness-shift topic, contrastive topic and familiar topic are base-generated in the broad $\mathrm{C}$-domain ${ }^{2}$. Moreover, he proposes that the broader C-domain contains "speaker" (logophoric agent $-\Lambda_{\mathrm{A}}$ ) and "hearer" (logophoric patient $-\Lambda_{\mathrm{P}}$ ) features, which are silent but syntactically active (Sigurðsson 2004, 2011, 2014). These logophoric features and the Top features are C/edge-linking features or C/edge linkers (CLn).

The $\mathrm{C} /$ Edge-Linking Generalisation states that any definite argument, overt or silent, positively matches at least one CLn in its local C-domain (Sigurðsson 2011: 282). Matching takes place under Agree (see Chomsky 2001). Definite $1^{\text {st }}, 2^{\text {nd }}$ or $3^{\text {rd }}$ person arguments in the T-domain match the "speaker", "hearer" or topic features in the C-domain, thereby being respectively valued as $\left[+\Lambda_{\mathrm{A}}, \ldots\right],\left[+\Lambda_{\mathrm{P}}, \ldots\right],[+\mathrm{Top}, \ldots]$. Indefinite arguments do not match the $\mathrm{C} /$ edge-linking features.

The C-domain of any finite clause contains a set of C/edge linkers which may be independently valued. This is the case of prototypical main clauses (cf. Sigurðsson 2011) where the speaker refers to himself with the pronoun " $I$ " and to the hearer with the pronoun "you". See example (1):

$$
\begin{aligned}
& \text { I like you. } \\
& {\left[_ { \mathrm { CP } } \ldots \{ \Lambda _ { \mathrm { A } } \} _ { 1 } \ldots \{ \Lambda _ { \mathrm { P } } \} _ { \mathrm { m } } \ldots \left[_{\mathrm{TP}} \ldots I_{1} \ldots \text { you }_{\mathrm{m}} \ldots\right.\right.}
\end{aligned}
$$

The C/edge linkers may be valued also in relation to categories in the preceding linguistic context. This may be seen in direct speech in English (see example 2), as well as in many other languages.

$$
\begin{aligned}
& \text { Tony said to Harry: "I likeyou”. } \\
& {\left[_ { \mathrm { CP } } \ldots \{ \Lambda _ { \mathrm { A } } \} _ { 1 } \ldots \{ \Lambda _ { \mathrm { P } } \} _ { \mathrm { m } } \ldots \left[_{\mathrm{TP}} \ldots \text { Tony }_{\mathrm{i}} \ldots \text { Harry }_{\mathrm{j}} \ldots\right.\right.} \\
& { }_{\mathrm{CP}} \ldots\left\{\Lambda_{\mathrm{A}}\right\}_{\mathrm{i}} \ldots\left\{\Lambda_{\mathrm{P}}\right\}_{\mathrm{j}} \ldots\left[_{\mathrm{TP}} \ldots I_{\mathrm{i}} \ldots \text { you }_{\mathrm{j}} \ldots\right.
\end{aligned}
$$

${ }^{2}$ I adopt Sigurðsson's architecture of the left periphery of the sentence throughout the paper for expository purposes. I will not take a stance on what specific template of the left periphery should be preferred. 
The $1^{\text {st }}$ and $2^{\text {nd }}$ person pronouns in subordinate clauses in direct speech match the speaker and hearer features $\ldots\left\{\Lambda_{A}\right\}_{i} \ldots\left\{\Lambda_{P}\right\}_{j}$, which inherit their reference from arguments in the matrix clause in example (2). The subject of the direct speech clause in example (2) does not match the speaker - the logophoric agent of the main clause - as it was the case in example (1). The deictic switch in direct speech shows that context linking is not only a matter of pragmatics, but also has to be a syntactic phenomenon. The speaker and hearer features in the embedded clauses redefine the reference of speaker and hearer from the main clause.

In a given perceptual and discourse situation there are usually many possible persons or objects that may be referred to by arguments in a given utterance, but their $\phi$-features must be computed clause-internally and they have to match $\mathrm{C}$-features in order to be interpreted. In order to capture this phenomenon, Sigurðsson (2011: 283) distinguishes between reference and the mechanism of C/edge linking: "While arguments are $\phi$-computed under CLn matching in narrow syntax, their definite reference is decided by clause-external context scanning, either under distant Agree/control [...] or by extrasyntactic means". The phases as the minimal computational domains of language (Chomsky 2001) are equipped according to Sigurðsson (2014: 175) with silent linking edge features that enable narrow syntax to link to context and build the structures of broad syntax.

\section{C/edge linking of null arguments in different languages}

The first type of null arguments, pro drop, isconditioned by subject-verb or object-verb agreement, e.g. Romance null subjects. The null arguments of this type have the same referential properties and distribution as weak pronouns in such languages as German or English (Cardinaletti \& Starke 1999; Roberts 2009). Similarly to pronouns, null subjects of pro drop type can be preceded by an adverb (see 3):

a. Today she hits a ball.

b. Oggi colpisce un pallone. Today hits- $3^{\text {rd }}$ person a ball

'Today she hits a ball.'
(English, German etc.)

(Italian etc.)

In accordance with Alexiadou \& Anagnostopoulou (1998) as well as Sigurðsson (2011) I will therefore analyse verbal agreement in the structures with this type of null argument as pronouns, incorporated in $\mathrm{T}\left(\varnothing-\mathrm{T}_{\phi}\right){ }^{3}{ }^{3} \mathrm{The} \phi$-features are visible, null arguments of the pro drop type are therefore not true null anaphora. They are visible $\phi$-bundles which are identifiable across clause boundaries (see 4):

3 I adopt the symbol fromSigurðsson (2011) where the dash indicates that two elements constitute one phonological unit. 
(4) Gianni vede che colpisce un pallone. (Italian etc.)

Gianni sees that hits-3 ${ }^{\text {rd }}$ person a ball

'Gianni sees that she/he hits a ball.'

Pronouns as well as $\varnothing-\mathrm{T}_{\phi}$ both enter an Agree relation with one of the CLn features (see 5):

a. She hits a ball. $\left[_{\mathrm{CP}} \ldots\{\mathrm{CLn}\} \ldots \ldots \ldots \ldots\left[_{\mathrm{TP}} \frac{\text { she }}{4} \mathrm{~T} \ldots\right.\right.$

b. Colpisce un pallone. hits $-3^{\text {rd }}$ person a ball

(English, German etc.)

'She/He hits a ball.'

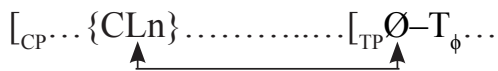

(Italian etc.)

In neither case does the presence or absence of an overt element in Spec, $C$ affect the grammaticality of the structures, showing that $\mathrm{C} /$ edge linking of $\phi$-visible arguments may be accomplished across lexical categories (see 6):

Oggi colpisce un pallone.

(Italian)

Today hits- $3^{\text {rd }}$ person a ball

'Today he/she hits a ball.'

$\mathrm{C}_{\mathrm{CP}} \ldots\{\mathrm{CLn}\} \ldots$ oggi....... $\mathrm{I}_{\mathrm{TP}} \varnothing-\mathrm{T}_{\phi} \ldots$

The second type of null arguments, e.g. null topics, has a much more constrained distribution than the weak pronouns and null subjects of Romance type. Null subjects or objects in Germanic have to be in the topic position and a lexical element in Spec,C makes the structure ungrammatical in German (see 7):
a. _Hab ich schon gesehen.
Have I already seen.
'I have already seen this.'
b. *Heute _ hab ich schon gesehen.
Today have I already seen.
'I have already seen this.'

(German)

Null topics cannot be interpreted as $\phi$-specified without being locally C/edge linked. The C/edge linking of the elements is blocked by the presence of a lexical Spec,C. Sigurðsson \& Maling (2010) as well as Sigurðsson (2011: 294) assume that the movement (internal Merge) of more than one constituent across the finite verb in $\mathrm{C}$ is blocked (see 8).

$$
\begin{aligned}
& \text { a. Hab ich schon gesehen. } \\
& {\left[{ }_{\mathrm{CP}} \ldots\{\mathrm{CLn}\} \ldots \ldots \ldots \ldots \ldots \ldots \varnothing\right.}
\end{aligned}
$$

(German) 
b. *Heute hab ich schon gesehen. $*\left[_{\mathrm{CP}} \ldots\{\overline{\mathrm{CL}}\} \ldots\right.$ heute.....

(German)

Successful C/edge linking of the null topics in V2 languages occurs only if the null arguments move to the $\mathrm{C}$-domain across a lexical $\mathrm{C}$. Otherwise, the lexical $\mathrm{C}$ intervenes between it and $\mathrm{CL}_{n}$ resulting in C/edge linking being uninterpretable (see structure 9):

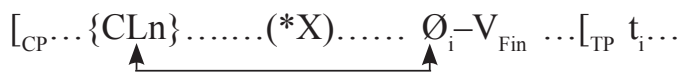

The third type of null arguments, discourse drop, is not clause-internally constrained. Null arguments can be discourse-linked, e.g. in Chinese, or controlled, this means antecedent-linked, e.g. Finnish definite $3^{\text {rd }}$ person null subjects. Sigurðsson (2011: 298) assumes that Chinese nullargumentsdo not need to raise into the $\mathrm{C}$-domain for the purpose of C/edge linking, as illustrated in (10) for null object in Chinese:

$$
\begin{aligned}
& \text { Piotr zěnme chǔlì zhège tāng ne? } \\
& \text { What did Peter did with the soup? } \\
& \text { Hē le. } \\
& \text { Drink } \\
& \text { 'He ate it.' } \\
& {\left[_ { \mathrm { CP } } \ldots \{ \mathrm { CLn } \} \ldots \ldots \left[_ { \mathrm { TP } } \ldots \left[_{\mathrm{vP}} \ldots .\right.\right.\right.}
\end{aligned}
$$

(Chinese)

Finnish null subjects, e.g. antecedent-linked null arguments, have to move across a lexical C in order to match CLn, see example (11) from Sigurðsson (2011: 294, 295):

$$
\begin{aligned}
& \text { Pekka }_{i} \text { väittää ettää }{ }_{-i *_{j}^{*}} \text { puhuu englantia hyvin. (Finnish) } \\
& \text { Pekka claims that _ speak }{ }_{3 \mathrm{rd} \mathrm{SG}} \text { English well } \\
& \mathrm{NP} \ldots\left[_ { \mathrm { CP } } \ldots \{ \mathrm { CLn } \} \ldots \varnothing _ { - } - \text { ettää } \ldots \left[_{\mathrm{TP}} \mathrm{t}_{\mathrm{i}} \ldots\right.\right. \\
& \text { control }
\end{aligned}
$$

To sum up, the effects of C/edge linking mechanism can be seen in different languages. In various language systems additional surface factors contribute to the distribution of null and overt arguments as well. The distribution patterns of all three types of null arguments, e.g. pro drop, topic drop and discourse drop, prove that the approach treating null arguments as bundles of syntactically active but silent features is on the right track.

\section{C/edge linking of null arguments in Polish}

\subsection{Null subjects in Polish}

Polish grammar allows for referential null subjects (see also Pisarkowa 1969; Saloni 1976). Null subjects in Polish are the first type of null arguments - pro drop. They are conditioned by subject-verb agreement. The verbal paradigm in Polish is quite rich. It encodes person as well as number (see 12). 
(12) Polish verbal paradigm in present

$\begin{array}{ll}1^{\text {st }} \mathrm{SG} \text { robie } & 1^{\text {st }} \mathrm{PL} \text { robimy } \\ 2^{\text {nd }} \mathrm{SG} \text { robisz } & 2^{\text {nd }} \mathrm{PL} \text { robicie } \\ 3^{\text {nd }} \mathrm{SG} \text { robi } & 3^{\text {nd }} \mathrm{PL} \text { robia }\end{array}$

In the past tense the verbal affixes also encode gender. This rich verbal paradigm ensures that Polish null subjects are PF-visible and interpretable. Therefore, I will analyse the verbal agreement in Polish structures with null subject as pronouns, incorporated in $\mathrm{T}\left(\varnothing-\mathrm{T}_{\phi}\right)$, similarly to null subjects in Romance languages. As referential arguments, Polish null subjects have to be successfully C/edge linked (see 13).

(13) Uderza piłke.

hits- $3_{\text {SG }}^{\text {rd }}$ ball

'She hits the ball.'

$\left[_{\mathrm{CP}} \ldots\{\mathrm{CLn}\} \ldots\left[_{\mathrm{TP}} \varnothing-\mathrm{T}_{\phi} \ldots\right.\right.$

Polish null subjects are identifiable across clause boundaries, in which they also resemble $\phi$-overt pronouns in Germanic languages and null arguments in Romance languages (see 14).

(14) Kasia ${ }_{i}$ widzi, że ${ }_{i}$ uderza piłkę.

Kasia sees $3^{\text {rd }}{ }_{\text {SG fem }}$ that

'She sees that she hits the ball.'

In an appropriate context the $\varnothing-\mathrm{T}_{\phi}$ in the subordinate clause can refer not to the subject of the matrix clause but to other persons known from previous linguistic or situational context (see example 15).

a. Gdzie jest Jan?

Where is $3^{\text {rd }}{ }_{\text {SG }} \operatorname{Jan}_{i}$

'Where is Jan??'

b. Piotr ${ }_{j}$ twierdzi, że $-i$ wyjechał.

Piotr $_{j}$ claims that ${ }_{-i}$ left $3^{\text {rd }}{ }_{\text {SG masc }}$

'Piotr ${ }_{j}$ claims that he ${ }_{i}$ left.'

\subsection{Null objects in Polish}

Some cases of missing objects may be analyzed by dint of the verb-stranding VP-ellipsis in Polish (e.g. Ruda 2014). Such analysis is, however, only possible in contexts with a linguistic antecedent for VP. This present study exclusively concerns the cases of null objects independent of VP ellipsis. Moreover, further discussion will exclusively concern referential null objects, i.e. cases where the reference of the null objects is recoverable from the context. 
In the past tense in Polish verbs may be perfective and imperfective in aspect. In the imperfective aspect verbs exhibit optional transitivity, which can lead to the ambiguity of the utterances. Without context, the transitive use of an imperfective verb with null object and the intransitive use of the verb are indistinguishable on the surface. In the perfective aspect transitive verbs may not be used intransitively in Polish (see Kotin 2003) similarly to Russian (see Babko-Malaya 1999) and in contrast to such languages as Greek (see Tsimpli \& Papadopoulou 2006). Due to the meaning "end of the activity" or "change of state" which is connected with the perfective aspect, perfective transitive verbs may not be generic in interpretation. The reference of the null object following perfective transitive verbshas to be recoverable from the context. To avoid ambiguity, all the verbs in the examples below will be perfective transitive verbs in the past tense.

Polish grammar allows for referential null objects when the referent is given information (see also Pisarkowa 1969; Ruda 2014; Saloni 1976). Null objects in Polish are, unlike null subjects, not clause-internally constrained (Kowaluk 1999; Tryzna 2015; Mykhaylyk \& Sopata 2016; Sopata 2016). There is no object-verb agreement in Polish. The object drop in Polish is then a $\phi$-silent type of argument drop (see 16).

a. Co Jan zrobił z lodem?

'What did Jan with the ice cream?'

b. Zjadt_.

ate

'He ate it.'

Null objects in Polish do not have to be in the topic position. The default position of the direct object expressed by lexical NPs, pronouns or null elements is the postverbal position in Polish sentences (see example 17)

a. Co Jan zrobit z lodem?

'What did Jan with the ice cream?'

b. Zjadt loda/go/.

ate ice cream/it ${ }_{\mathrm{CL}} /$

'He ate the ice cream/it.'

The object drop in Polish is not topic drop, as can also be clearly seen in sentences in which the preverbal position is occupied (see 18).

(18) a. Kiedy Jan zjadt loda?

'Whan did Jan eat the ice cream?'

b. Wczoraj zjadt.

yesterday ate $3_{\text {SG masc }}^{\text {rd }}$

'He ate it yesterday.' 
The object drop in Polish is therefore a case of discourse drop. Objects are easily dropped in colloquial Polish, not only in answers to appropriate questions as in the examples above, but also in narrative contexts, as illustrated in (19):

(19) Jan otworzył list. Przeczytał go/_ i wyrzucił go/ _.

Jan opened $3^{\text {rd }}{ }_{\text {SG masc }}$ letter. Read $3^{\text {rd }}{ }_{\text {SG masc }}$ it/_ and threw away $3^{\text {rd }}{ }_{\text {SG masc }}$ it/_

'Jan opened the letter. He read it and threw it away.'

Objects may also be expressed as nulls, whenever the referent is highly salient in the further pragmatic context (see example 20):

a. Co z tym?

What about this? (pointing to an empty plate on which there were cookies earlier)

b. Jan zjadt_.

Jan ate ${ }^{\text {rd }}$ SG masc

'Jan ate them/the cookies.'

In Polish, it is possible unlike in other null object languages, e.g. European Portuguese (see Cardinaletti 1990), to drop the objects of verbs in Polish, not only in the $3^{\text {rd }}$ person but also in some contexts in the $1^{\text {st }}$ and the $2^{\text {nd }}$. Consider the following examples (21) and (22):

a. Co on z toba zrobit?

'What did he do to you?'

b. Zniszczyt

destroyed $3^{\text {rd }}$ SG masc

'He destroyed me.'

(22) a. Co on ze mna zrobit?

'What did he do to me?'

b. Zniszczyt

destroyed $3^{\text {rd }}{ }_{\text {SG masc }}$

'He destroyed you.'

In most contexts null objects freely alternate with pronouns in Polish (Kowaluk 1999; Tryzna 2015; Mykhaylyk \& Sopata 2016; Sopata 2016). Whenever the cognitive status of the referent is highly activated in the speaker's mind, by means of prior discourse or high saliency in the pragmatic context, the object may be expressed by a null. In some contexts, using null objects seems, however, to lead to ungrammaticality orinfelicitous utterances, even thoughthe referent is highly activated in the speaker's mind. So, using 
a null argument in the object position and a pronoun in the subject position in a context similar to example (16) above leads to an infelicitous utterance (see 23):

(23) a. Co Jan zrobił z lodem?

'What did Jan with the ice cream?'

b. *On zjadt.

he ate $3^{\text {rd }}$ SG masc

'He ate it fast.'

This seems puzzling because it is not so that the verbs cannot be accompanied by any other elements in clauses with null objects. Objects can be dropped from sentences where verbs are modified by some adverbials as can be seen in (24):

(24) a. Co Jan zrobił z lodem?

'What did Jan with the ice cream?'

b. Szybko zjadt.

fast ate $3^{\text {rd }}$ SG masc

'He ate it fast.'

In contexts where the subject is the focus of attention ${ }^{4}$, however, the possibility with a realised subject and dropped object is grammatical again, as illustrated in (25):

a. Kto zjadt loda?

'Who has eaten the ice cream?'

b. Jan/On zjadt .

$\mathrm{Jan} /$ he ate ${ }^{\text {rd }}{ }_{\text {SG masc }}$

'Jan/He has eaten it.'

In order to explain the distribution pattern of null objects in Polish let us consider the $\mathrm{C} /$ edge linking mechanism of null arguments. The computation of null objects as well as null subjects is constrained by specific syntactic, discourse and pragmatic principles. More specifically, they have to be computed through a syntactic channel in order to be appropriately interpreted. Referential null objects, as well as null subjects, must be successfully $\mathrm{C} /$ edge linked, this means they have to be linked with $\mathrm{C} /$ edge linkers that are valued in relation to prior discourse and pragmatic context (see example (16b) repeated as (26):

(26) Zjadt.

ate $3^{\text {rd }}{ }_{\text {SG }}$

${ }^{4}$ On Focus in Polish, see Tajsner 2015. 
'He ate it.'

$\left[_{\mathrm{CP}} \ldots\{\mathrm{CLn}\} \ldots\left[_{\mathrm{TP}} \varnothing-\mathrm{T}_{\phi} . . \varnothing(\mathrm{obj}) \ldots\right.\right.$

Example (26) is the answer to the question 'What did Jan do with the ice cream?' as in example (16) above. The subject is thus the primary topic and the object the secondary topic of the discourse in accordance with Givon (1984). Therefore, the arguments from the example (26) match the primary and secondary Familiar Topics (see 27).

$$
\left[\mathrm{CP} \ldots 1 \text { FamTop... 2FamTop... } \mathrm{T}_{\mathrm{TP}} \varnothing-\mathrm{T}_{\phi} \ldots \varnothing(\mathrm{obj}) \ldots\right.
$$

The C/edge linking of the subject and direct object in the answer to the same question proceeds similarly if both arguments are expressed as definite NPs or pronouns (see example 28).

\section{Jan/On zjadt loda/go.}

$\mathrm{Jan} / \mathrm{On}$ ate $3_{\text {SG }}^{\text {rd }}$ ice cream/it

'Jan/He ate the ice cream/it.'

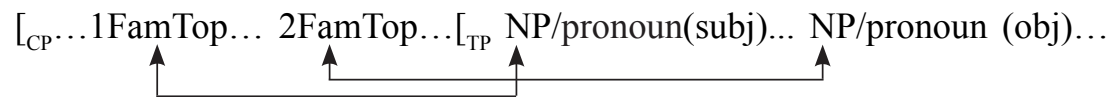

C/edge linking cannot be accomplished, however, if the subject is realised not as $\varnothing-\mathrm{T}_{\phi}$ but as a regular pronoun or NP and the object is dropped. The subject expressed by a pronoun or NP intervens in C/edge linking of the null object if both are familiar topics as is illustrated in (29).

a. Co Jan zrobił z lodem?

'What did Jan with the ice cream?'

b. *On/Jan zjadt_.

$\mathrm{He} / \mathrm{Jan}$ ate ${ }^{\text {rd }}{ }_{\text {SG masc }}$

'He/Jan ate it fast.'

* $\left[_{\mathrm{CP}} \ldots 1\right.$ FamTop... 2FamTop... $\left[_{\mathrm{TP}} \mathrm{NP} /\right.$ pronoun(subj)... Ø (obj)...

In not allowing C/edge linking of null object across a full pronoun or NP subject if the subject is a familiar topic Polish seems to resemble Swedish and Icelandic (see Sigurðsson 2011: 288 for the discussion of Swedish and Icelendic). The structurally high subject intervenes in successful CLns matching of vP-null objects.

The C/edge linking of a null object is, however, possible again, once the subject is in focus, as illustrated by the grammaticality of (25) repeated as (30). The subject in focus seems to have the property of left-dislocated elements and to occupy a structurally higher position than $\{C \operatorname{Ln}\}$ and therefore it does not intervene between $\{C \operatorname{Ln}\}$ and $\varnothing$. The C/edge matching of the null object is then possible, as sketched in (30): 
a. Kto zjadt loda?

'Who has eaten the ice cream?'

b. Jan/On zjadt

$\mathrm{Jan} /$ he ate ${ }^{\text {rd }}{ }_{\text {SG masc }}$

'Jan/He has eaten it.'

$\left[_{\mathrm{CP} \ldots}\right.$ Foc NP/Pronoun(subj)... FamTop..... $\left[_{\mathrm{TP}} \ldots \varnothing(\mathrm{obj}) \ldots\right.$

In allowing $\mathrm{C} /$ edge linking of a null object across focussed subjects and not allowing it across a full pronoun or NP if the subject is a familiar topic Polish seems to resemble Swedish and Icelandic, as well. Given the differences between the characteristics of Swedish and Icelandic null arguments (null topics) on the one hand and of Polish null arguments (null subjects - pro drop and null objects discourse drop) on the other hand, the similarity points to the necessity of a unitary approach to computation of null arguments.

\section{Summary and conclusion}

The main objective of the foregoing discussion has been to examine whether Polish data can be explained on the basis of C/edge linking theory. The central claim of the theory is that all definite arguments must be successfully C/edge linked, e.g. they have to match at least one feature in the broad C-domain. Null arguments, as well as overt arguments, have to be linked to the speaker, hearer or one of the topic features. The distribution patterns of null arguments is, moreover, constrained by such factors as V2 effects or presence of elements acting as an intervener for C/edge linking.

The use of null subjects and objects in Polish is consistent with the main claims of the C/edge linking theory. Moreover, assuming null objects to be bundles of active but silent features makes the analysis of Polish utterances with null in direct object position more plausible. The distributional patterns of pronoun or null objects in Polish can be interpreted as an indicator for the existence of silent edge linkers.

It follows also from the discussion above that, despite many differences between various languages, language systems share a significant part of argument computation which can be stated in terms of C/edge linking mechanism. The use of referential expressions depends on pragmatic context but referential null arguments arealso syntactically constrained.

\section{References}

Alexiadou, Artemis \& Anagnostopoulou, Elena. 1998. Parametrizing Agr: Word order, V-movement and EPP-checking. Natural Language and Linguistic Theory 16. 491-539.

Ariel, Mira. 1990. Accessing noun-phrase antecedents. Routledge: New York.

Arnold, Jennifer \& Griffin, Zenzi. 2007. The effect of additional characters on choice of referring expression: everyone competes. Journal of Memory and Language 56. 521-536. 
Babko-Malaya, Olga. 1999. Zero morphology: a study of aspect, argument structure and case. New Brunswick: The State University of New Jersey. (Doctoral dissertation.)

Cardinaletti, Anna. 1990. Subject/Object asymmetries in German null-topic constructions and the status of SpecCP. In Mascaro, Joan \& Nespor, Marina (eds.), Grammar in progress: GLOW essays for Henk van Riemsdijk, 75-84. Dordrecht: Foris.

Cardinaletti, Anna \& Starke, Michal. 1999. The typology of structural deficiency: A case study of the three classes of pronouns. In van Riemsdijk, Henk (ed.), Clitics in the languages of Europe, 145-233. Berlin: Mouton de Gruyter.

Chomsky, Noam. 1957. Syntactic Structures. The Hague: Mouton.

Chomsky, Noam. 2001. Derivation by phase. In Kenstowicz, Michael (ed.), Ken Hale: A life in language, 1-52. Cambridge, MA: MIT Press.

Frascarelli, Mara. 2007. Subjects, topics and the interpretation of referential pro. An interface approach to the linking of (null) pronouns. Natural Language Linguistic Theory 25. 691-734.

Fukumura, Kumiko \& van Gompel, Roger \& Pickering, Martin. 2010. The use of visual context during the production of referring expressions. The Quarterly Journal of Experimental Psychology 49A. 991-1004.

Givon, Thomas. 1984. Syntax. A Functional-Typological Introduction. Volume 1. Amsterdam: Benjamins.

Grosz, Barbara, \& Joshi, Aravind \& Weinstein, Scott. 1995. Centering: a framework for modeling the local coherence of discourse. Computational Linguistics 21(2). 203-225.

Gundel, Jeanette \& Hedberg, Nancy \& Zacharski, Ron. 1993. Cognitive status and the form of referring expressions in discourse. Language 69(2). 274-307.

Haegeman, Liliane \& Hill, Virginia. 2013. The syntacticization of discourse. In Foli, Raffaella \& Sevdali, Christina \& Truswell, Robert (eds.), Syntax and its Limits, 370-390. Oxford Scholarship Online.

Holmberg, Anders. 2005. Is there a little pro? Evidence from Finnish. Linguistic Inquiry 36. 533-564.

Huang, C.-T. James. 1984. On the distribution and reference of empty pronouns. Linguistic Inquiry 15. 531-574.

Huang, C.-T. James. 1991. Remarks on the status of the null object. In Freidin, Robert (ed.), Principles and Parameters in Comparative Grammar, 56-76. Cambridge, MA: MIT Press.

Kotin, Michaił. 2003. Die werden-Perspektive und die werden-Periphrase im Deutschen. Historische Entwicklung und Funktionen in der Gegenwartssprache. Frankfurt a. M.: Peter Lang.

Kowaluk, Agnieszka. 1999. Null objects in Polish: Pronouns and determiners in second language acquisition. Working Papers in English and Applied Linguistics 6. 135-152.

Mykhaylyk, Roksolana \& Sopata, Aldona. 2016. Object pronouns, clitics, and omissions in child Polish and Ukrainian. Applied Psycholinguistics 5(37). 1051-1082.

Pisarkowa, Krystyna. 1969. Funkcje składniowe polskich zaimków odmiennych. Wrocław: Zakład Narodowy im. Ossolińskich.

Roberts, Ian. 2009. A deletion analysis of null subjects. In Biberauer, Theresa \& Holmberg, Anders \& Roberts, Ian \& Sheehan, Michelle (eds.), Parametric variation: Null subjects in minimalist theory, 58-87. Cambridge: Cambridge University Press.

Ruda, Marta. 2014. On the V-stranding VP ellipsis analysis of missing objects in Polish. In Surányi, Balazs \& Turi, Gergo (eds.), Proceedings of the Third Central European Conference in Linguistics for Postgraduate Students, 60-85. Pázmány Péter Catholic University.

Saloni, Zygmunt. 1976. Cechy składniowe polskiego czasownika. Wrocław: Zakład Narodowy im. Ossolińskich.

Serratrice, Ludivica. 2013. The role of number of referents and animacy in children's use of pronouns. Journal of Pragmatics 56. 31-42.

Sigurðsson, Halldor Armann. 2004. The syntax of person, tense, and speech features. Italian Journal of Linguistics 16. 219-251.

Sigurðsson, Halldor Armann. 2010. On EPP effects. Studia Linguistica 64. 158-189.

Sigurðsson, Halldor Armann. 2011. Conditions on argument drop. Linguistic Inquiry 42. 267-304.

Sigurðsson, Halldor Armann, 2014. Context-linked grammar. Language Sciences 46. 175-188.

Sigurðsson, Halldór Ármann \& Maling, Joan. 2010. The Empty Left Edge Condition. In Putnam, M. (ed.), Exploring Crash-Proof Grammars, 59-86. Amsterdam: John Benjamins.

Sopata, Aldona. 2016. Null objects in adult and child Polish: Syntax, discourse and pragmatics. Lingua 183. 86-106.

Speas, Margaret. 2004. Evidentiality, logophoricity and the syntactic representation of pragmatic features. Lingua 114. 255-276. 
Tajsner, Przemysław. 2015. On focus marking and predication. Evidence from Polish with some notes on Hausa. Lingua Posnaniensis 57(1). 113-138.

Tsimpli, Ianthi \& Papadopoulou, Despina. 2006. Aspect and argument realization: A study on antecedentless null objects in Greek. Lingua 116. 1595-1615.

Tryzna, Marta. 2015. Acquisition of object clitics in child Polish: Evidence for three developmental stages. Lingua 161. 67-81. 